\title{
Gêneros, multimodalidade e letramentos ${ }^{1}$ Genres, Multimodality, and Literacies
}

Zulmira Medeiros*

Universidade Federal de Minas Gerais (UFMG)

Belo Horizonte - Minas Gerais / Brasil

RESUMO: Este trabalho apresenta uma análise da multimodalidade em um ambiente virtual de aprendizagem, bem como da apropriação de novos gêneros discursivos e do letramento acadêmico vivenciado por alunos de um curso de graduação semipresencial. O objetivo foi compreender as relações que os sujeitos constroem entre si e com o próprio ambiente multimodal por meio da escrita online. Os resultados demonstraram que a multimodalidade influencia as escolhas, a navegação e a própria escrita. Percebemos que o texto e o discurso produzidos por esses sujeitos nesse ambiente modificam-se ao longo do tempo, influenciados que são pelas relações que estabelecem entre si, com a própria tecnologia e com o meio acadêmico.

PALAVRAS-CHAVE: multimodalidade, letramento acadêmico, gênero discursivo.

ABSTRACT: This paper presents an analysis of multimodality in a virtual learning environment as well as the appropriation of new genres and academic literacy experienced by students in an undergraduate blended course. The objective was to understand the relationships that individuals construct among themselves and with the multimodal environment itself through online writing. The results demonstrated that multimodality influences choices, navigation, and one's own writing style. It could be observed that the text and the discourse produced by these individuals in this environment are modified over time, influenced by the relationships established among themselves, with the technology itself, and with academia.

KEYWORDS: multimodality, academic literacy, genre.

*zulmiram@ufmg.br

${ }^{1}$ Este artigo foi organizado a partir da tese de doutorado intitulada Letramento digital em contextos de autoria na internet (MEDEIROS, 2011) construída sob a orientação da professora Silvania Sousa do Nascimento (FaE/UFMG). 


\section{INTRODUÇÃO}

Este estudo insere-se em uma pesquisa de doutorado, na qual investigou-se a constituição de uma prática discursiva em um ambiente virtual de aprendizagem, buscando-se compreender as relações entre a participação em contextos de autoria e o processo de letramento vivenciado. Os sujeitos, ao participarem desse espaço, estavam interagindo entre si, construindo e publicando sua escrita, sendo, deste modo, autores, editores e leitores. Ao tratar da escrita autoral em diferentes espaços no ambiente virtual de aprendizagem, consideramos os gêneros discursivos que ali se constituíam, além de elementos que atuam na construção dessa escrita, como a presença de imagens e o próprio leiaute da tela, que também nos chamaram a atenção, no sentido de compreender as escolhas que o sujeito é levado a fazer. Deparamo-nos, assim, com a concepção de linguagem como um fenômeno histórico e socialmente constituído, fortemente ancorada na realidade imediata e no contexto mais amplo. Nesse sentido, encontramos na obra de Mikhail Bakhtin (1997, 2006) orientações condizentes com nossos objetivos e que passaram a referenciar o nosso quadro metodológico.

O estudo empírico deu-se entre os alunos da primeira oferta (20082011) do curso de graduação em Pedagogia, realizado na modalidade semipresencial, pela Universidade Aberta do Brasil - UAB e pela Universidade Federal de Minas Gerais - UFMG, funcionando, então, em nove polos localizados em diferentes municípios do interior do Estado de Minas Gerais. Em cada polo foram constituídas duas turmas de 25 alunos, totalizando cerca de 450 alunos, sujeitos desta pesquisa. Integra a metodologia do curso a utilização de um ambiente virtual da aprendizagem (neste caso, a plataforma MOODLE), onde pode ser mantido um contato via internet entre coordenação, tutores e alunos, por meio de chats, fóruns, envio de mensagens e publicação de conteúdos, assim como postagem, pelos alunos, das atividades solicitadas. Os dados foram coletados por meio de questionários online e da observação virtual e analisados a partir dos pressupostos da filosofia da linguagem - segundo a abordagem bakhtiniana, conforme será apresentado ao longo do texto. A análise da prática discursiva deu-se a partir dos textos construídos e publicados pelos sujeitos nos fóruns, wikis e blogs, no ambiente virtual de aprendizagem, ao longo dos 4 anos de curso.

Este texto apresenta-se organizado de maneira a não explicitar uma separação, na estrutura dos tópicos, do referencial teórico e dos dados 
empíricos, para, como de costume, estabelecer um diálogo entre esses elementos somente nos momentos de análises e/ou considerações finais. Diferentemente, sempre que possível, apresentamos as orientaçôes teóricas dialogando com os dados coletados, buscando, ali mesmo, realizar as análises e inferências que se mostraram pertinentes. Abordaremos, inicialmente, a rede de conceitos em torno dos gêneros discursivos, em seguida, as implicações acerca da multimodalidade presente no ambiente investigado e, ao final, os processos de letramento explicitados em nossas análises.

\section{GÊNEROS DISCURSIVOS}

A definição de gênero possui suas origens na antiguidade (gêneros poético, jurídico, político) e nas tradições literárias (poesia, narrativa, teatro, romance). $\mathrm{Na}$ análise do discurso e na análise textual, a noção de gênero assume diferentes perspectivas, de acordo com determinados posicionamentos teóricos, tais como um ponto de vista funcional, enunciativo, textual ou comunicacional (CHARAUDEAU e MAINGUENEAU, 2004, p.249-250). É na perspectiva comunicacional que situamos os estudos sobre gênero neste texto, sob um campo teórico constituído em torno dos trabalhos de Bakhtin (1997, 2006), Kress (1989, 2003) e Marcuschi (2007).

Segundo Bakhtin (1997, p.279), "cada esfera de utilização da língua elabora seus tipos relativamente estáveis de enunciados, sendo isso que denominamos gêneros do discurso". Em sua obra, os enunciados são tratados como a unidade real da comunicação verbal / discursiva, um produto da enunciação que, por sua vez, pode ser vista como o contexto em que o discurso se constitui. $\mathrm{O}$ enunciado seria, pois, uma sequência verbal, de extensão variável, cujas fronteiras seriam definidas pela alternância entre os sujeitos falantes. Desse modo, a utilização da língua, em todas as esferas da atividade humana, dá-se por meio de enunciados, orais ou escritos.

Enquanto em Bakhtin encontramos um amplo trabalho em torno dos gêneros discursivos, no sentido de evidenciar "o dialogismo do processo comunicativo" e "as relações interativas como processos produtivos de linguagem” (MACHADO, 2007, p.152), Marcuschi (2007) demonstra uma preferência pelo uso do termo gêneros textuais, definindo-o como textos materializados em nosso cotidiano. Ao buscarmos pela abordagem de gêneros desenvolvida por Marcuschi, encontramos primeiramente a distinção entre gêneros e tipos textuais. Tal distinção favorece a compreensão da natureza social constitutiva dos gêneros textuais, justamente por evidenciar, por outro 
lado, a natureza linguística constitutiva dos tipos textuais. Marcuschi (2007) utiliza a expressão tipo textual "para designar uma espécie de construção teórica definida pela natureza linguística de sua composição (aspectos lexicais, sintáticos, tempos verbais, relações lógicas)" (p.22). Em relação à expressão gênero textual, o autor a utiliza como uma

noção propositalmente vaga para se referir aos textos materializados que encontramos em nossa vida diária e que apresentam características sociocomunicativas definidas por conteúdos, propriedades funcionais, estilo e composição característica (MARCUSCHI, 2007, p.22-23).

Segundo esse autor, nos gêneros também estão presentes os tipos textuais, podendo ocorrer que o mesmo gênero realize dois ou mais tipos. Assim, quando nomeamos um texto como narrativo ou argumentativo, na verdade não estamos nomeando o gênero, mas o predomínio de algum tipo de sequência textual de base. Notamos que Marcuschi define gênero textual não por suas especificidades linguísticas e estruturais, mas por suas funções comunicativas, cognitivas, institucionais e interativas nas práticas sociodiscursivas. Em Bakhtin (1997) também encontramos uma forma da organização e análise da constituição dos gêneros:

O enunciado reflete as condições específicas e as finalidades de cada uma dessas esferas, não só por seu conteúdo (temático) e por seu estilo verbal, ou seja, pela seleção operada nos recursos da língua - recursos lexicais, fraseológicos e gramaticais —, mas também, e sobretudo, por sua construção composicional. Estes três elementos (conteúdo temático, estilo e construção composicional) fundem-se indissoluvelmente no todo do enunciado, e todos eles são marcados pela especificidade de uma esfera de comunicação (BAKHTIN, 1997, p.279).

Notamos que, para Bakhtin, tanto o conteúdo temático e o estilo verbal quanto a construção composicional são elementos característicos e constitutivos dos gêneros do discurso. Como Bakhtin afirma, por ser a atividade humana algo imensurável, a multiplicidade de gêneros do discurso também o é, já que cada uma das esferas da comunicação verbal apresenta um conjunto característico de gêneros do discurso, que se amplia e se modifica na medida em que esse meio se complexifica. Dependendo da finalidade ou da função do texto e das condiçôes de sua produção em cada uma dessas esferas, novos gêneros vão sendo constituídos, do ponto de vista temático, composicional e estilístico (BAKHTIN, 1997). 
Nesse sentido, reconhecemos tal processo na escrita autoral nos ambientes virtuais de aprendizagem. Nesse ambiente, podemos dizer que um novo gênero se constitui, guardando estreitas relações com as definições já aceitas pela linguística, principalmente de sua função comunicacional (COSCARELLI, 2006). Entretanto, essa escrita apresenta alguns aspectos que lhe são particulares, tais como: a multiplicidade de linguagens que compõem o texto (imagens, sons, links, animações, vídeos, o próprio texto escrito e outros); novos formatos de escrita como no chat - informal, sincronizada e composta de signos presentes apenas nesse meio; novas formas de interações e direções que permeiam uma conversa no fórum, ou seja, a sua não linearidade; novas relações entre os interlocutores, menos verticalizadas e menos formais, dentre outros.

Bakhtin (1997) estabelece uma classificação dos gêneros discursivos em primários e secundários. Os gêneros primários são os de natureza mais simples, oriundos das situações de comunicações discursivas naturais, cotidianas, espontâneas, não são ensinados (conversas e diálogos do dia a dia). Já os gêneros discursivos secundários são os de natureza mais complexa, oriundos das situações comunicativas construídas, relativamente mais produzidas e evoluídas, principalmente escritas (teatro, textos científicos, discurso político, etc.). Os gêneros secundários ao se formarem, absorvem e transformam os gêneros primários, que perdem, então, a sua relação com a realidade imediata e espontânea.

Neste ponto, sabemos que no ambiente virtual, mesmo tendo a escrita como suporte, tanto um fórum quanto um chat, em geral, possuem uma estrutura discursiva próxima da linguagem oral. Entretanto, nos fóruns a conversação é assíncrona, ao contrário dos chats, onde a conversação é sincrônica. $\mathrm{O}$ texto produzido e enviado pelo fórum possui uma estrutura que lhe é peculiar, podendo apresentar-se mais extenso, elaborado, com menos abreviações, ou seja, menos marcado pelo imediatismo da conversação no chat. Consideramos que, assim como nos fóruns, o conteúdo postado nos wikis e nos blogs está mais próximo da linguagem escrita justamente por poder apresentar um texto que representa um pensamento construído previamente, mesmo que os níveis de formalidade e estruturação sejam variáveis. Tais textos ficam, a nosso ver, num ponto intermediário entre os gêneros primários e os secundários, pois não perdem inteiramente a relação com a realidade imediata e com a espontaneidade, embora se deem em situações de comunicação construídas no contexto de um curso de 
graduação a distância. As mensagens a seguir, postadas pela aluna Denise ${ }^{2}$ em diferentes sequências comunicativas demonstram como a escrita online é marcada por outros gêneros discursivos e pela transição entre a linguagem oral e a linguagem escrita, entre gêneros primários e gêneros secundários:

\author{
Mensagem postada pela aluna Denise ( $3^{\circ}$ semestre letivo) \\ Fórum Hora do Cafezinho \\ Reiterando o que foi dito pelos meus colegas <nomes de três colegas>, fiquei \\ surpresa e insegura com a noticia, mas estou satisfeita com [...] \\ Cordialmente, agradeço desde já pela compreensão de todos. \\ Atenciosamente Denise Maria Gonçalves.
}

Mensagem postada pela aluna Denise ( $5^{\circ}$ semestre letivo)

Fórum Hora do Cafezinho

Oi colega, eu também estou com muitas saudades, mas como você mesma disse

[...], mas olha eu estou aqui ... olha colega e mamãe como está passando desejo melhoras... beijos Denise

Sem centrar-se no conteúdo ou na forma, a classificação dos gêneros respalda-se, isto sim, na ação social (propósitos, funções, intenções, interesses) em que ele aparece para realizar-se. Os gêneros vão, pois, se constituindo no fazer do dia a dia, como fruto de um trabalho coletivo, no uso da língua em diferentes contextos, reflexos de estruturas sociais recorrentes e típicas de cada cultura. Mudanças sociais, históricas, culturais e tecnológicas possibilitam e favorecem a ampliação e o surgimento de novos gêneros e formas de comunicação oral e escrita. Como afirma Marcuschi, "isto é revelador do fato de que os gêneros textuais surgem, situam-se e integram-se funcionalmente nas culturas em que se desenvolvem" (2007, p.20). Por essa natureza social, os gêneros textuais são, por um lado, maleáveis, dinâmicos e plásticos: eles surgem, desaparecem, se transformam, se cruzam e, normalmente, se constituem ancorados uns nos outros. Por outro lado, independem de decisões individuais e não são facilmente manipuláveis: são resultado de determinações sociocomunicativas. Trata-se de formas socialmente desenvolvidas em práticas comunicativas que dão ordem e estabilidade à comunicação cotidiana por se ancorarem em modelos comunicativos (MARCUSCHI, 2007).

\footnotetext{
${ }^{2}$ Em todas as transcriçôes, neste texto, os nomes dos sujeitos foram alterados, no intuito de preservar a sua identidade.
} 
A escrita num ambiente virtual de aprendizagem dentro de um curso de graduação a distância traz consigo marcas da comunicação escolar em um suporte tecnológico diferenciado, que coloca os sujeitos em contato entre si por meio dessa escrita. $\mathrm{O}$ texto e o discurso produzidos por esses indivíduos nesse ambiente modificam-se ao longo do tempo, influenciados que são pelas relações que os sujeitos estabelecem entre si, com a própria tecnologia e com o meio acadêmico.

Alinhado com o que Bakhtin aborda em torno das esferas da atividade humana, Marcuschi (2007) traz o conceito de domínio discursivo, designando-o como "uma esfera ou instância de produção discursiva ou de atividade humana [..] em que os textos circulam” (p.23-24). Dentro dos domínios discursivos, identificamos os gêneros textuais institucionalizados, próprios daquele domínio ou por vezes exclusivos a ele. Assim, Marcuschi percebe os gêneros como "formas verbais de ação social relativamente estáveis realizadas em textos situados em comunidades de práticas sociais e em domínios discursivos específicos" (p.25).

Embora possamos perceber a ancoragem histórico-social em ambas as definiçôes, algo parece não estar bem delineado. Num primeiro momento, Marcuschi parece dar maior atenção à materialidade textual quanto à forma (estrutura textual) e ao propósito comunicativo (função, interesses), enquanto Bakhtin deixa em evidência os elementos de natureza comunicacional da troca verbal, enfatizando as situações de produção. Num segundo momento, somos levados a considerar que ambos tratam de objetos sociocomunicativos e discursivos semelhantes, constituídos nas interações verbais, porém, o fazem em diferentes contextos e com nomenclaturas distintas. Até porque Marcuschi (2007) afirma que, embora sejam eventos linguísticos, os gêneros textuais caracterizam-se como atividades sociodiscursivas. Tal aproximação justifica nossa opção em dialogar com esses autores, mantendo nosso foco na análise nos aspectos comunicacionais que nos deem pistas das relações entre os sujeitos e destes com o contexto. Fazemos, assim, a opção pelo termo gênero discursivo sem nos desfazermos do que aqui foi apresentado em torno do termo gênero textual, interessando-nos mais pelos aspectos que os aproximam do que pelos que os distinguem.

Percebemos que a compreensão em torno dos vocábulos texto e discurso interessa a este estudo. Para Marcuschi (2007), o texto é "uma entidade concreta realizada materialmente e corporificada em algum gênero textual" (p.24), enquanto discurso "é aquilo que um texto produz ao se manifestar 
em alguma instância discursiva. [...] o discurso se realiza nos textos" (p.24). Em Kress (1989 e 2003) também encontramos a indicação das categorias texto, gênero e discurso, no sentido de enfatizar a conexão entre processos linguísticos e sociais. Segundo o autor, não se pode apenas considerar o ponto de vista do falante, do escritor, de quem produz o texto, mas também pensar sobre como o texto é lido ou ouvido, como é reconstruído ou entendido. $\mathrm{E}$, ainda, sobre as razôes da escrita, por que falantes e escritores falam ou escrevem, como eles imaginam falar ou escrever. Kress nos lembra que, na educação, é muito importante se pensar sob tais perspectivas, pois (a) os processos educacionais são processos linguística e comunicativamente constituídos e (b) na educação, estamos tratando da transmissão de culturas I contextos sociais em sua forma verbal, por isso, entender o texto, sua constituição, construção e efeitos é muito importante. O ouvinte e o leitor, o falante e o escritor, são agentes sociais envolvidos em uma rede de relaçóes sociais - em lugares específicos da estrutura social.

Para Kress, compreender as diferenças entre os modos e formas de falar e de escrever só e possível sob uma perspectiva linguística e social. Assim, pode-se perceber que o indivíduo compartilha práticas, valores, significados, demandas de um determinado grupo ou instituição social. A educação é um bom exemplo - as pessoas compartilham um tipo específico de linguagem, em determinados momentos, em determinadas situações. E esse tipo de linguagem apresenta similaridades nas palavras, expressões e forma de dizer ou de escrever - uma gramática característica do grupo - onde os significados sociais são linguisticamente expressados, caracterizando o discurso daquele grupo.

Conforme dissemos anteriormente, o contexto de um curso de graduação a distância, juntamente com as características provenientes de diferentes redes sociais e culturais, diferentes trajetórias familiares, escolares e profissionais, certamente marcam a escrita dos sujeitos em um ambiente virtual de aprendizagem. Ao longo de sua vida, o indivíduo convive com diferentes discursos - na família, na escola, no trabalho - e leva consigo traços desses discursos associados aos lugares sociais que esse indivíduo ocupou / experimentou / vivenciou, já que "a história social / discursiva dos indivíduos, bem como a sua posição social atual, determinam o seu acesso ao conjunto de discursos em uma sociedade" (KRESS, 1989, p.12, tradução nossa ${ }^{3}$ ).

${ }^{3}$ Texto original em inglês: "The social/discoursive histories of individuals, as well as their 
Também, para Kress, conhecer o contexto é importante para se compreender o texto e o discurso que ali se constituem. $\mathrm{O}$ autor utiliza o termo social occasions para caracterizar os aspectos do ambiente, os participantes, os interesses envolvidos, indicando que cada um desses componentes possui seus efeitos sobre os gêneros que são construídos naquela situação. Para o autor, as situações são mais ou menos controladas / formalizadas / estruturadas / ritualizadas (cerimônia de casamento, festa, almoço em família, reunião de trabalho, aula, conversa no corredor, etc.). As formas convencionalizadas da ocasião social resultam em formas convencionalizadas de texto, ou seja, em gêneros. Assim, os gêneros possuem formas e significados que derivam e refletem as funçôes, interesses e significados da ocasião social. Os textos apresentam não somente os significados do discurso de que fazem parte, mas também do gênero. $\mathrm{O}$ primeiro relaciona-se à natureza da instituição de que provém, o segundo, acerca das convençôes da ocasião social dada:

Tanto discurso quanto gênero carregam significados específicos e socialmente determinados. O discurso carrega significados sobre a natureza da instituição de que é derivado; o gênero carrega significados sobre as ocasiōes sociais convencionais em que surge o texto (KRESS, 1989, p.20, tradução nossa $\left.{ }^{4}\right)$.

Nos espaços de autoria no ambiente virtual de aprendizagem, as características e funçóes daquela ocasião social e o propósito dos participantes certamente contribuem, dando forma e significado aos gêneros que ali se constituem, são refletidos e codificados neles. Do mesmo modo, os papéis que os participantes desempenham na interação e as relações de poder são constituintes do gênero. Um resultado da influência da diferença de poder é quão aberta ou fechada é uma interação. Quanto maior a diferença de poder, mais fechada é a interação. Quanto menor, mais aberta. Essa correlação influencia a forma (gênero) e os aspectos linguísticos do texto que resulta dessa interação.

present social position, determine their access to the set of discourses in a society" (KRESS, 1989, p.12).

${ }^{4}$ Texto original em inglês: "Both discourse and genre carry specific and socially determined meanings. Discourse carries meanings about the nature of the institution from which is derived; genre carries meanings about the conventional social occasions on which text arise." (KRESS, 1989, p.20). 
Kress resume que a descrição dos aspectos formais de um gênero e a descrição de todo um sistema linguístico em ação no texto não se dão em apenas um ou dois aspectos, mas na totalidade das formas linguísticas. $\mathrm{O}$ discurso determina o que é dito, o gênero determina como vai ser dito em determinado contexto, conforme completa: "Discurso e gênero são fatores distintos, apesar do fato de que ambos estão constantemente presentes em conjunto na forma linguística.” (KRESS, 1989, p.29, tradução nossa ${ }^{5}$ ).

Por fim, outro ponto comum entre os autores citados neste tópico é a noção de inacabamento, de fronteiras indefinidas na classificação e categorização dos gêneros. Na definição de Bakhtin (1997), vemos os gêneros discursivos como "tipos relativamente estáveis de enunciados" e em Marcuschi (2007) os gêneros textuais são definidos como uma "noção propositalmente vaga para se referir aos textos materializados”. Kress (2003) também afirma não existirem gêneros puros, mas misturas, pois a linguagem em uso é sempre socialmente e culturamente formada, o que faz do texto e do gênero uma mistura, algo dinâmico.

Reforçamos a perspectiva com que tratamos o conceito de gênero e discurso neste estudo, no intuito de caracterizar uma relação entre o texto e seu contexto situado no tempo e no espaço. Importa-nos compreender mudanças nas práticas discursivas que indiquem o processo de letramento vivenciado pelos sujeitos. As tecnologias, os suportes tecnológicos e os usos que deles se faz vão favorecendo o surgimento de novos gêneros discursivos, certamente ancorados em gêneros anteriores, que são absorvidos e transformados nesse processo. Os gêneros discursivos característicos da web refletem muito bem essa transmutação ao apresentar, na forma escrita, situações comunicativas que trazem muitas características da oralidade.

\section{A MULTIMODALIDADE NO AMBIENTE VIRTUAL DE APREN- DIZAGEM}

Ao estudarmos a escrita nos contextos de autoria num ambiente virtual de aprendizagem, deparamo-nos com as influências dos aspectos multimodais desse ambiente sobre a escrita de nossos sujeitos. Neste tópico, apresentaremos como a multimodalidade está presente em nosso contexto

\footnotetext{
${ }^{5}$ Texto original em inglês: "Discourse and genre are discrete factors despite the fact that both are constantly present together in linguistic form." (KRESS, 1989, p.29).
} 
de pesquisa e quais as relações entre os elementos que compõem a tela e a escrita que nela se dá.

Num cenário em que a tela é o meio dominante e em que o visual é o modo que prevalece, a escrita apresenta uma nova orientação, com novas formas e funções. De acordo com Kress (2003 e 2010), alguns anos atrás, a lógica da escrita dava forma ao livro e às suas páginas. Uma lógica da temporalidade, onde palavras, sentenças e parágrafos são organizados um após o outro, numa sequência temporal. Já a tela e o que nela aparece é uma entidade visual, onde a lógica da espacialidade é que determina a organização dos elementos. O livro era dominado pela lógica da escrita e a tela é dominada pela lógica da imagem. Consequentemente, a escrita na tela vai se apresentando sob a lógica visual.

Ao investigarmos os contextos de autoria (fóruns, blogs e wikis) em nossa pesquisa, percebemos que a escrita, mesmo que alfabética, é também iconográfica e, ainda, que é possível produzir-se sentidos a partir desses aspectos iconográficos. Isso significa multiplicar significados por meio dos recursos dos modos visuais, onde diversos elementos concorrem e contribuem para a produção de sentidos - textos, imagens, cores, disposição, leiaute, etc.

Estamos, pois, trazendo à tona o conceito de multimodalidade (KRESS e VAN LEEUWEN, 1996; KRESS, 2003 e 2010). Para esses autores, o texto multimodal é aquele cujo significado se realiza por mais de um código semiótico. Isso nos leva a entender que não se caracteriza como multimodal apenas o texto que contém imagens, gráficos, tabelas, etc. Palavras, espaçamentos de parágrafos e linhas, títulos, cores, caixa alta, enfim, elementos por vezes tomados como invisíveis ou transparentes, na verdade não o são. Podemos ter a imagem no sentido estrito, mas também o verbal como imagem, ou seja, diagramação, paragrafação, fundo colorido, leiaute, não são mera organização, produzem sentidos.

Num ambiente virtual, o texto em si, o suporte, o design da tela, o arranjo dos diversos itens, as formas, os tamanhos, as cores, tudo isso compõe a multimodalidade. Todos esses elementos vão para além da função estética, eles também participam da construção de sentido pelo sujeito, ajudam a definir as escolhas que serão feitas, a navegação, a escrita, como uma gramática visual. ${ }^{6}$ A tela (da TV, do computador, do data-show) tem se

${ }^{6}$ Gramática visual: termo utilizado por Kress (2003). 
tornado, então, elemento crucial nas representações, tornando-se um lugar privilegiado da multimodalidade, como Kress (2003) afirma: "A tela é o ambiente da imagem e a lógica da imagem domina a organização semiótica da tela" (p.65, tradução nossa ${ }^{7}$ ). Esse processo demanda um letramento diverso do letramento relacionado à comunicação verbal escrita de um modo geral. Nossos sujeitos de pesquisa estão se formando leitores e escritores de espaços interativos na web, pessoas que estão lidando com espaços multimodais, tão característicos da cultura letrada contemporânea. Aprender a lidar com isso é um processo socialmente construído, socialmente compartilhado.

Como nos lembra Kress (2003), "nós sempre fazemos uso dos recursos que nós temos disponíveis, para o propósito de construir as representações que nós desejamos ou precisamos fazer" (p.82, tradução nossa ${ }^{8}$ ), ou seja, os elementos visuais da tela, os links, os botôes, os caminhos, as formas de responder e de postar a sua mensagem... tudo isso constitui as condições de produção, as formas de interação e o próprio conteúdo das mensagens. $\mathrm{O}$ arranjo visual produz efeitos sobre a construção de sentido pelo usuário. $\mathrm{E}$, certamente, para muitos indivíduos esse ambiente não teve o mesmo significado, eles não construíram os mesmos sentidos, não se apropriaram da mesma maneira.

O conceito de multimodalidade é, pois, peculiar a este estudo, principalmente no que se refere ao entendimento das relações que o sujeito estabelece com o ambiente virtual e das relações que estabelece com seus pares por meio do ambiente virtual. Traremos a seguir, três exemplos construídos a partir de dados coletados na observação virtual e que podem ser interpretados à luz do conceito de multimodalidade e da produção de sentidos.

\section{A estrutura do fórum refletida no processo comunicativo}

Ao criar o fórum no ambiente virtual, o tutor pode selecionar a opção "fórum geral", em que todos podem abrir novos tópicos de discussão, ou a

\footnotetext{
7 Texto original em inglês: "[...] the screen is the site of the image, and the logic of the image dominates the semiotic organisation of the screen" (KRESS, 2003, p.65). 8 Texto original em inglês: "[...] we always draw on the resources which we have available to us, for the purposes of making the representations that we wish or need to make" (KRESS, 2003, p.82).
} 
opção "fórum como discussão única", em que novos tópicos só podem ser criados pelo tutor.

$\mathrm{Na}$ Figura 1, temos a imagem da tela de um fórum com vários tópicos criados pelos alunos. Notamos que o tema da discussão foi proposto pelo tutor na mensagem que se encontra na parte superior da tela e as pessoas vão criando novos tópicos, respondendo a essa questão inicial, bastando para isso clicar no botão "Acrescentar novo tópico de discussão", bastante visível abaixo da questão proposta.

\section{Oi, pessoal!}

Vamos dar início ao nosso primeiro fórum de discussões, que tem por tema a "identidade do professor". Insira seus comentários a partir de reflexões sobre esse tema. Sugerimos algumas questões norteadoras para a discussão: 0 que é ser professor? Quais são as características de professores que nos marcaram tanto positiva quanto negativamente? Com relação aos conteúdos que temos trabalhado nos guias, como podemos refletir sobre "identidade do professor" ?

\begin{tabular}{|c|c|c|c|c|}
\hline \multicolumn{5}{|c|}{ Acrescentar um novo tópico de discussão } \\
\hline Tópico & Autor & Comentários & s Não lida $\checkmark$ & Última mensagem \\
\hline Ser professor é... & 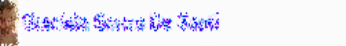 & 1 & 0 & 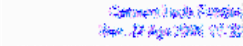 \\
\hline Identidade do professor & 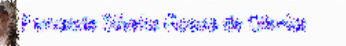 & 4 & 0 & 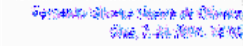 \\
\hline O que é ser professor & 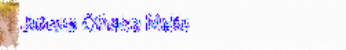 & 0 & 0 & 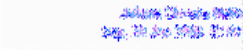 \\
\hline ser professor & 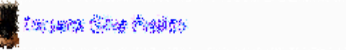 & 0 & 0 & 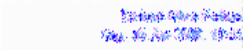 \\
\hline ser professor & 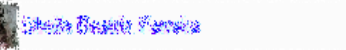 & 0 & 0 & 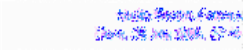 \\
\hline Identidade do professor & 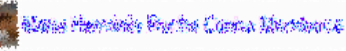 & 0 & 0 & 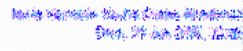 \\
\hline Identidade do Professor & 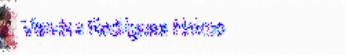 & 0 & 0 & 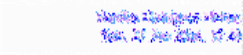 \\
\hline O que é ser professor & 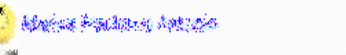 & 0 & 0 & 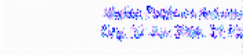 \\
\hline Identidade do professor & 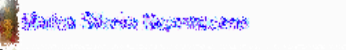 & 0 & 0 & 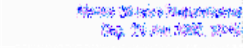 \\
\hline IDENTIDADE DO PROFESSOR & 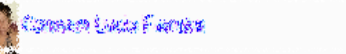 & 0 & 0 & 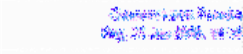 \\
\hline O que é ser professor? & 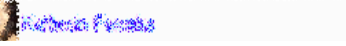 & 1 & 0 & 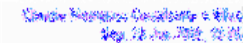 \\
\hline
\end{tabular}

Figura 1 - Imagem da tela de um fórum com tópicos criados pelos alunos. ${ }^{9}$

Nem todas as pessoas clicam no link de algum tópico já postado no intuito de comentar algo que alguém (que não seja o tutor) já escreveu. Isso pode ser visto na Figura 1, na coluna "Comentários", como muitos tópicos recebem poucos comentários ou não são comentados. A seguir, apresentamos

\footnotetext{
${ }^{9} \mathrm{Em}$ todas as figuras, as fotos e os nomes das pessoas foram ofuscados por um efeito visual, no intuito de preservar a identidade dos sujeitos da pesquisa.
} 
duas das mensagens postadas num fórum com tal estrutura, onde a questão proposta era a respeito da identidade docente:

Mensagem postada pela aluna Meire

Fórum: Identidade do Professor

Para mim, ser professor é ser estar sempre disposto também a aprender. Porque ninguém 'é o doutor sabe tudo', temos de ter humildade de reconhecer que o conhecimento é adquirido todos os dias e que às vezes quebramos a cabeça com determinada situação e uma criança acaba solucionando essa questão. Ser professor éser amigo, ser companheiro, um mediador do conhecimento.

Mensagem postada pela aluna Vera

Fórum: Identidade do Professor

Professor deve ser uma pessoa que conhę̧a cada aluno com problemas, suas qualidades e defeitos. Procurando corrigir e dando atenção aos alunos que mais precisarem.

Observa-se que em suas mensagens, as alunas procuram responder à questão proposta, numa resposta ao tutor. Mas na tela, tais mensagens, como muitas outras, são postadas em páginas separadas, e lá permanecem, como tarefas cumpridas, porém, sem que haja interação entre elas ou com mensagens anteriores, tampouco foram postadas em seguida mensagens que dialogassem com estas. Mesmo as pessoas que se dispōem a comentar em tópicos já criados, acabam não entrando em todos, até porque estão tratando da mesma questão proposta. Observamos que esse aspecto fez com que o processo comunicativo ficasse fragmentado, sem continuidade e sem um ponto de chegada sistematizado em um encerramento do fórum.

Já na Figura 2, temos a imagem de um fórum criado como discussão única, onde o botão "Acrescentar novo tópico de discussão" não está disponível para os alunos.

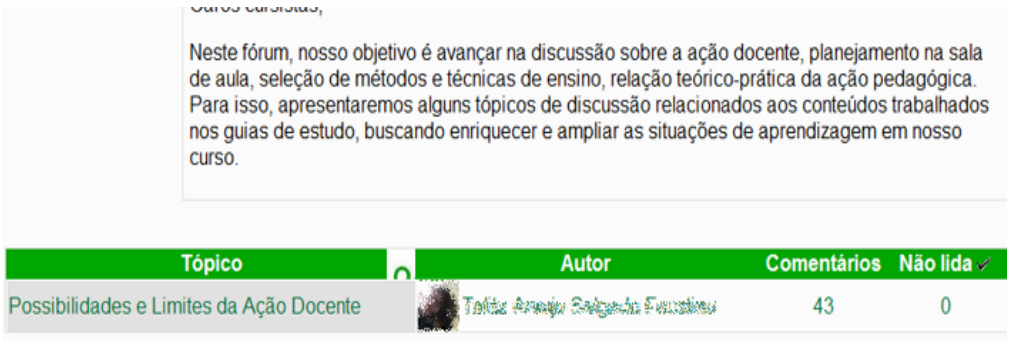

Figura 2 - Imagem da tela do fórum criado como discussão única. 
Nesse formato, o meio de postar um comentário é clicando no link do tópico criado pelo tutor, o que leva o sujeito à tela da discussão, apresentada na Figura 3.

Re: Proibido não tocar - crianças em contato com a obra de Bruno Munari

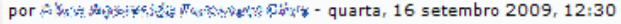

Bom dia Cis,

A criança precisa tocar aquilo que está vendo, para assimilar as idéias e, talvez, através do toque possa brot

Na minha sala, a coordenadora mandou que colocasse tudo ao alcance da criança, para ser tocado: alfabeto que ser trocado toda semana. Ela acha que a criança tendo contato, ela aprende mais rápido e com maior fa

Tudo para a criança tem que ser proibido não tocar, somente as coisas de risco e de periculosidade.

Abraços

ans

Re: Proibido não tocar - crianças em contato com a obra de Bruno Munari

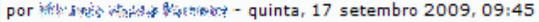

Concordo com a fiès, a criança aprende mais quando toca as imagens que vê, ela se familiariza, usando o fazer algo não precisamos pegar observar de perto, a mesma coisa acontece com as crianças. Faz parte da

Re: Proibido não tocar - crianças em contato com a obra de Bruno Munari por ring:

É muito importante que a criança toque nos objetos.É nesse momento que ela familiariza com os mesm com sua imaginação.

Re: Proibido não tocar - crianças em contato com a obra de Bruno Munari

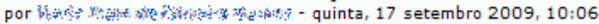

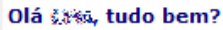

Concordo com a distinguir as formas, o peso, enfim as características em sí.

Muito legal esta produção.

Re: Proibido não tocar - crianças em contato com a obra de Bruno Munari

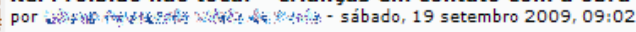

\#\%y achei super interessante a sua colocaçao, até nós adoramos tocar nas coisa, quem nao diria as cr brincadeiras em que as crianças desenvolve suas habilidades, destreza e satisfaz uma necessidade inte

Figura 3 - Imagem da tela interna do fórum criado como discussão única.

Estando nessa tela, o sujeito pode clicar no link "Responder" em qualquer das mensagens já postadas. Esse formato supõe que as pessoas leiam o que já foi escrito e que, ao escreverem suas mensagens, dialoguem com as mensagens anteriores. A seguir, apresentamos os excertos de cinco mensagens postadas consecutivamente, num fórum com tal estrutura: 
Mensagens postadas pelas alunas

Fórum: Múltiplas linguagens e interação social

Bom dia Beth, a criança precisa tocar aquilo que está vendo, para assimilar as ideias $e$, talvez, através do toque possa brotar inspiração para ideias novas. [...]. Abraços, Ana. (Ana, 16/09/2009).

Concordo com a Ana, a criança aprende mais quando toca as imagens que vê, ela se familiariza, usando o dedinho, seguindo o contorno das letras e números, facilita a escrita. [...] (Marta, 17/09/2009).

É muito importante que a criança toque nos objetos. É nesse momento que ela se familiariza com os mesmos, despertando a curiosidade, desenvolvendo suas habilidades e interesse de criar, de modificar, de acordo com sua imaginação. (Diana, 17/09/2009).

Olá Beth, tudo bem? Concordo com a Marta e a Ana, só acho engraçado uma coisa, não só as crianças como nós mesmos, tudo que vemos, sentimos a necessidade de tocar, e é tocando em algo que podemos distinguir as formas, o peso, enfim as características em si. Muito legal esta produção. (Neuza, 17/09/2009).

Neuza, achei super interessante a sua colocação, até nós adoramos tocar nas coisas, quem não diria as crianças. As crianças precisam sentir, tocar, experimentar, ouvir, olhar e se emocionar. [...] (Luana, 19/09/2009).

Observamos a presença de marcadores como "bom dia, Beth", "Concordo com a Ana", "achei super interessante a sua colocação". As pessoas falam entre si, se remetem ao que o outro já escreveu, seja para concordar, discordar ou complementar. Em outras palavras, esse formato do fórum pode favorecer que aconteçam essas trocas comunicativas, que haja maior interação.

O botão "Adicionar novo tópico de discussão", presente na Figura 1, pode ser caracterizado como um elemento gráfico, um bloco de texto, centralizadamente posicionado, que exerceu influência sobre a escolha entre criar um novo tópico ou comentar um tópico já criado. $\mathrm{O}$ botão praticamente induziu as alunas a postarem suas mensagens em páginas separadas e, desse modo, pouco ou nada dialogarem entre si. 
Ao acompanhar a escrita coletiva no wiki, por diversos momentos nos deparamos com a necessidade dos indivíduos em demarcarem as suas contribuições, de sinalizar para o leitor (tutor) que ele (aluno) realizou a atividade e que, de certa maneira, se responsabiliza por uma parte específica do texto. Na Figura 4, vemos a diferenciação pelo uso do negrito, itálico e sublinhado, além do nome inscrito ao final. Na Figura 5, o recurso de formatação não foi utilizado, mas sim a digitação em caixa alta, com todos os caracteres em maiúscula. Na Figura 6, a diferenciação entre os textos se tornou ainda mais explícita, por meio do uso de tamanhos e cores distintos.

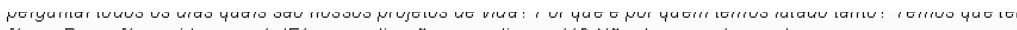
fé em Deus, fé na vida, em nós!Fé em realizações grandiosas, tá? Não devemos ter sonhos vagos e esperanças pequenas! Desejo que você nunca de sista, porque enquanto houver a esperança. nenhum sonho está perdido! Nenhum!

Realmente os nossos sonhos nunca podem morrer, ele dorme para acordar mais tarde. Para podermos realizar na hora certa,e os nossos sonhos, são investimentos que se tornarão bem sucedidos no futuro. Basta acreditar em si mesmo e é como a janela que abrimos todos os dias de manhá que vemos um novo dia .como uma nova oportunidade de aprender tudo que e novo...Se acreditarmos em DEUS tudo dará certo. Faça investimentos para aperfeiçoar a sua comunicação com o próximo.
\end{abstract}

Você nuca poderá desesperar com as dificuldades que encontrar pois quem confia no SENHOR sempre vencerá, porque o senhor sempre cumpre o que promete <sirlane>

DEUS nos concedeu a graça de estarmos juntos nesta caminhada

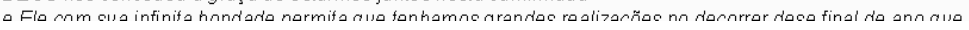

Figura 4 - Excerto de um texto produzido no wiki, com destaque para o trecho em itálico, negrito e sublinhado.

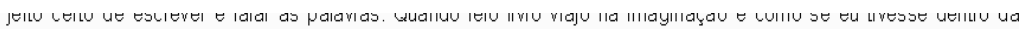
historia. E isso é muito bom, dá um prazer enorme e estimula a memória deixa-nos mais culto com vontade cada vez mais de ler. Todos os pais devem mostrar aos seus filhos o quanto é bom ler e se interessar pela leitura.

SABEMOS QUE NOSSO DEVER É O DE TÄO SOMENTE ESTIMULAR NOSSOS ALUNOS A LEITURA, PORÉM ANTES DISSO É IMPORTANTE SERMOS LEITORES CRITICOS E ASSIDUOS. O PROFESSOR PRECISA. TER AMPLO CONHECIOMENTO NA AREA DA LEITURA PARA ASSIM SABER O LIVRO CERTO PARA CADA FAIXA ETÁRIA, POIS TEMOS QUE ENCANTAR O ALUNO E SEDUZI-LO A ESTE MUNDO. É IMPORTANTE QUE SE FALE EM LEITURA E QUE SE PRÁTICA, PARA QUE NÄO CAIA NO BLÁBLÁBLÁ, ONDE EXISTE UMA ENORME DISTÂNCIOA ENTRE PRÁTICA E TEORIA, A NOSSA FALA DEVE SER SEMPRE A NOSSA PRÁTICA, PARA QUE NÄO NOS APRESENTEMOS DE FORMA INCOERENTE PERANTE NOSSOS ALUNOS. O PROFESSOR É QUEM CONSTRÓE SUA FORMAÇÃO, NINGÚEM PODE FAZERISSOÖ A NÄO SER VOCÊ MESMO.
\end{abstract}

Figura 5 - Excerto de um texto produzido no wiki, com destaque para o trecho em caixa alta. 


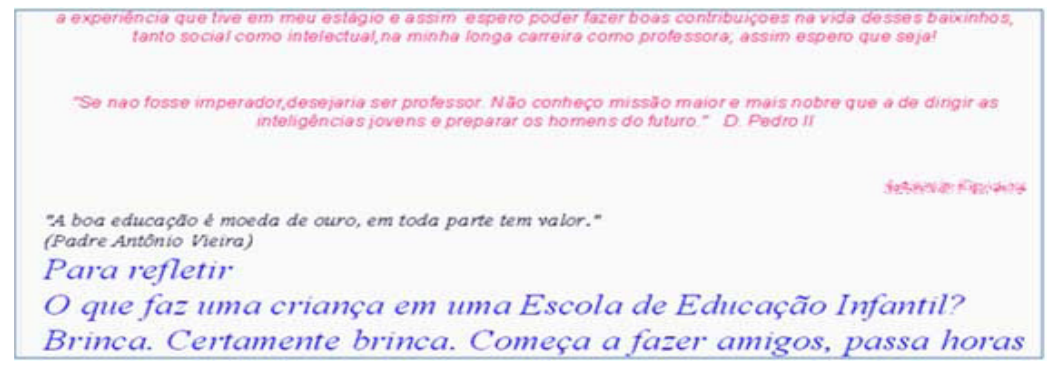

Figura 6 - Excerto de um texto produzido no wiki, com destaque para letras de fontes, tamanhos e cores diferenciados.

Podemos perceber que, na maioria dos casos, os sujeitos se preocuparam em dar continuidade ao texto, mas também quiseram que seu texto se diferenciasse dos demais, e para isso fizeram uso de diferentes estratégias. O que essa distinção significa para esses sujeitos é algo que nos instiga ao observar tais excertos. Se a proposta inicial era a construção de um texto em grupo, uma escrita coletiva que culminasse na produção de um único texto, não é coerente a diferenciação das partes do texto, de forma a identificar o que cada um escreveu. Percebemos que os recursos gráficos de formatação do texto foram utilizados não no sentido de dar uma unidade ao texto, mas, ao inverso, de dividi-lo em blocos de textos graficamente identificados.

Elementos não textuais como apoio às práticas discursivas

Outro ponto para importantes análises acerca da multimodalidade são as aberturas de alguns dos fóruns temáticos, em que eram trazidos elementos adicionais para iniciar ou fomentar a discussão. Dentre tais elementos, temos textos, vídeos e imagens, conforme apresentado no Quadro 1. 


\section{QUADRO 1}

Fóruns temáticos e respectivos elementos de discussão.

\begin{tabular}{|c|c|c|c|}
\hline & Título & Texto de abertura & $\begin{array}{l}\text { Elemento } \\
\text { de apoio }\end{array}$ \\
\hline 1 & O texto e o leitor & $\begin{array}{l}\text { Assistam ao vídeo: } \\
\text { <http://www.youtube.com/watch?v=IJq-x2Vrv8c> } \\
\text { A partir do vídeo e da leitura dos guias, vamos discutir sobre o } \\
\text { tema "O texto e o leitor". }\end{array}$ & Vídeo \\
\hline 2 & $\begin{array}{l}\text { Docência e } \\
\text { organização } \\
\text { escolar }\end{array}$ & $\begin{array}{l}\text { Nosso objetivo neste fórum é aprofundar a reflexão sobre } \\
\text { docência, articulando as questões tratadas nos diferentes } \\
\text { componentes deste módulo. Para isso, ASSISTA ao vídeo } \\
\text { clicando no link: } \\
\text { A organização do tempo e do espaço na escola. } \\
\text { Depois de assistir o vídeo, PARTICIPE do fórum comentando-o } \\
\text { e relacionando-o com os conteúdos do guia, especialmente, com } \\
\text { aqueles que abordam a constituição do sistema educacional } \\
\text { brasileiro e o papel do professor ao longo da história. }\end{array}$ & Vídeo $^{10}$ \\
\hline 3 & $\begin{array}{l}\text { Do memorial } \\
\text { à monografia }\end{array}$ & $\begin{array}{l}\text { Vamos, primeiramente, LER o texto "O PEIXE E A } \\
\text { FRIGIDEIRA", anexo nesta mensagem. } \\
\text { Depois de ler o texto, vamos CONVERSAR... } \\
\text { O que você achou do texto? Qual parte você gostou mais? } \\
\text { Em que você acha que o texto pode contribuir com o nosso } \\
\text { trabaho? [...] }\end{array}$ & Texto \\
\hline 4 & $\begin{array}{l}\text { Múltiplas linguagens } \\
\text { e Interações Sociais }\end{array}$ & $\begin{array}{l}\text { Nesta atividade, nosso objetivo é avançar na discussão } \\
\text { sobre variações lingüísticas, sobre linguagem não-verbal, } \\
\text { aprofundando em questões relacionadas à linguagem como um } \\
\text { aspecto social e histórico das interações humanas. } \\
\text { Vamos, primeiramente, OBSERVAR a imagem abaixo. } \\
\text { E então, O que você achou dessa obra de arte? Como podemos } \\
\text { relacionar essa imagem com as múltiplas linguagens? }\end{array}$ & Imagens \\
\hline
\end{tabular}

Fonte: Curso de Pedagogia UAB/UFMG.

${ }^{10} \mathrm{O}$ título do link estava direcionado à URL: <http://www.dominiopublico.gov.br/pesquisa/ DetalheObraForm.do?select_action=\&co_obra=20287 > . 
Algo notável foi que, inicialmente, as pessoas se prenderam à apreciação do elemento de apoio, descrevendo-o e relacionando-o com situações da vida cotidiana ou com o próprio tema do fórum.

Mensagem postada pela aluna Adriana (17/10/2008)

Fórum: $\mathrm{O}$ texto e o leitor

O vídeo nos mostrou a dificuldade que temos com o novo, tudo que é novidade, que é novo, de momento nos assusta. [...].

Mensagem postada pela aluna Suzana (06/06/2009)

Fórum: Do memorial à monografia

O texto é muito interessante, pois nos leva a procurar entender as origens de certas coisas que por hábito repetimos sem entender o porquê [...].

Mensagem postada pela aluna Vilma (06/09/2009)

Fórum: Múltiplas linguagens e interação social

Ao ver essa obra de arte entendi que há várias formas de linguagem. A imagem me passou que todos estão reunidos para chegar a um só objetivo.

Nessas mensagens, há um aspecto marcante nas primeiras sentenças, com presença de elementos tais como: "o vídeo nos mostrou", "este vídeo traz", "o texto é muito interessante", "achei que é uma obra de arte onde". Tais sentenças demonstram a centralidade que o elemento disparador da discussão tomou, ocupando, inclusive, o lugar da interação, já que as pessoas deixam de comentar o que os outros já escreveram, preocupadas em expor o que elas mesmas perceberam. Em alguns casos, a discussão só avançou a partir da inserção (normalmente pelos tutores) de novas questôes que instigassem a abordagem dos temas propostos nos guias impressos ou de situaçôes da prática escolar.

É fato que não se pode ignorar o importante papel desses elementos (textos, vídeos, imagens etc.) inseridos nas discussôes, proporcionando o diálogo entre os conteúdos curriculares presentes nos textos impressos e outros objetos de aprendizagem, oriundos de diferentes fontes. Essa contextualização também esteve presente nas argumentações que os alunos construíam em suas mensagens.

Analisando a forma como a multimodalidade se constitui e participa da constituição do ambiente virtual de aprendizagem, construímos um mapa conceitual (Figura 7), sistematizando a descrição e a interpretação dos exemplos apresentados: 


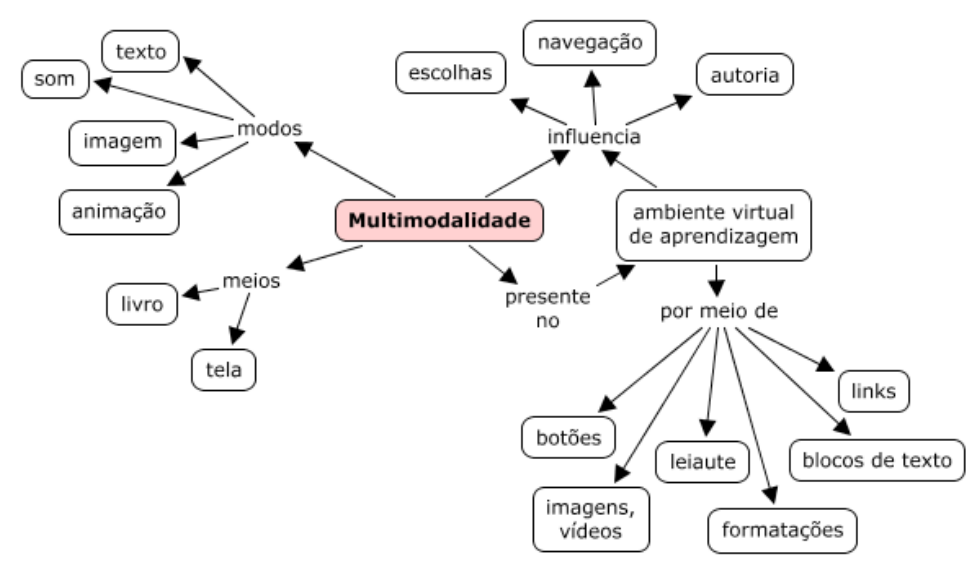

Figura 7 - Multimodalidade - mapa conceitual.

\section{MULTIMODALIDADE E GÊNERO}

Ao falarmos das mudanças de uso dos modos (da escrita para a imagem) e dos meios, (do livro para a tela) estamos também falando de uma mudança de gênero textual. A lógica da escrita é uma lógica sequencial, uma lógica temporal relacionada à estrutura textual, pois no texto escrito há um caminho de leitura a ser seguido. Já na imagem, a lógica é da espacialidade e não há um único caminho de leitura a ser seguido - a imagem pode ser lida em diferentes sequências. Não se trata, pois, de um gênero da escrita, mas de um novo gênero, um gênero visual, um gênero da tela. E é esse gênero que predomina na tela, mesmo que nela estejam também textos escritos.

$\mathrm{Na}$ tela, o caminho de leitura está aberto e é aí que se encontra o trabalho imaginativo do leitor, na criação da ordem de leitura. Vemos que no texto escrito, a leitura é de certa forma conduzida por um caminho já determinado. Na tela, a ordem da leitura, o caminho a ser seguido, encontrase aberto (às vezes mais, às vezes menos). É certo, pois, que as decisões sobre onde clicar, por onde navegar, que caminho seguir são demandadas ao leitor mais do que num texto escrito. Não quer dizer que a imagem esteja substituindo o texto escrito ou que a tela esteja substituindo o livro impresso. O que se observa é que os novos meios de comunicação e as novas mídias, impressas e digitais, favorecem uma crescente preferência pelo uso e pelo reconhecimento do modo visual. 
A multimodalidade presente no ambiente virtual de aprendizagem, por meio dos elementos gráficos que compõem o leiaute, por meio dos recursos gráficos que estão disponíveis aos usuários influencia diretamente a relação que esses sujeitos estabelecem com o próprio ambiente. E, ainda, as relações entre os próprios indivíduos, já que estas se materializam por meio do leiaute e dos usos que são feitos dos recursos disponíveis.

Diante da tela, cabe ao leitor, implicitamente, uma pergunta: como eu leio essa página? Não é uma página que o deixa livre dessa decisão, ele precisa escolher por onde começar. A tela do ambiente virtual de aprendizagem, com seus blocos de texto, seu links, seu leiaute, todos juntos perguntam ao indivíduo: o que você deseja? Por onde quer começar? Na tela do fórum com ou sem o botão "Adicionar novo tópico de discussão" ele toma uma decisão influenciado por um elemento gráfico, um bloco de texto que o leva a postar uma mensagem sem ler as mensagens anteriores. Na tela do wiki, o recurso tecnológico não é capaz de envolvê-lo em uma escrita coletiva, mas, contrariamente, facilita que ele identifique o seu texto, demarque fronteiras. Os elementos visuais (imagens, vídeos, textos anexos) por vezes roubam a cena nas interaçōes dos fóruns.

Essa organização da página mostra que a tela, diferentemente de uma página convencional, pode ter a navegação, a leitura e a escrita como uma problemática, algo em aberto, para o leitor/autor escolher. A tela está organizada na lógica do visual, com blocos gráficos, blocos de texto, fazendo com que ler e escrever na tela seja muito diferente do que ler e escrever na página de papel. A escrita vai, assim, se modificando, se adaptando às regularidades que aquela cultura adota, às regularidades daquele gênero.

Todo esse processo é muito importante quando discutimos a autoria na escrita online e, ainda, quando a relacionamos às condições de letramento manifestadas pelo sujeito.

\section{LETRAMENTOS MÚLTIPLOS}

Podemos observar que o ambiente virtual de aprendizagem se apresenta como locus para a produção de um sistema complexo de interações. Não estamos diante de relaçôes estáveis e homogêneas, cujas trocas comunicativas se dão de maneira simétrica e já determinada. Tampouco os enunciados que materializam essa comunicação verbal podem ser considerados neutros, pois o enunciado nunca é neutro, traz sempre consigo uma relação com a realidade, com o próprio autor e com os seus interlocutores (BAKHTIN, 1997). 
Compreendemos essas práticas discursivas, assim como Spink (2004, p.38), como os momentos de construção, de ressignificação, pois “implicam ações, seleções, escolhas, linguagens, contextos, enfim, uma variedade de produções sociais das quais são expressão". A autora diferencia os termos discurso e práticas discursivas, atribuindo ao primeiro o caráter de regularidade, como os discursos institucionalizados, mesmo que também tenham suas variações ao longo do tempo e de acordo com os diferentes contextos. Para Spink, as práticas discursivas representam rupturas e produções de sentido, num uso ativo da linguagem como mediação entre os interlocutores e destes com o contexto.

Nos fóruns, as relaçôes entre os interlocutores demonstraram, inicialmente, uma referência muito forte à submissão do aluno ao professor, já que as primeiras participações traziam sempre a conotação de se estar escrevendo para o tutor, o diálogo era com ele. Ao longo do tempo, a interação entre alunos foi se fazendo mais presente. O Quadro 2 apresenta trechos de mensagens postadas pela aluna Ana Paula, ao longo do curso, nos fóruns temáticos, onde eram propostas, pelo tutor, discussões acerca de temas relacionados aos conteúdos apresentados nos guias impressos do curso. 


\section{QUADRO 2}

\section{Excertos de mensagens postadas por uma mesma aluna nos fóruns temáticos ao longo do curso.}

\begin{tabular}{|c|c|}
\hline $1^{\circ} \mathrm{SL}$ & $\begin{array}{l}\text { Caro professor, Eduardo. } \\
\text { Boa Noite, } \\
\qquad \text { Eu, sinto que o professor é a base sólida para o nosso começo, ele faz parte [...]. } \\
\text { Abraços, } \\
\text { Sua Aluna, } \\
\text { Ana Paula Freitas Soares. }\end{array}$ \\
\hline $2^{\circ} \mathrm{SL}$ & $\begin{array}{l}\text { Professor Edu, } \\
\text { Boa Noite, } \\
\quad \text { Ao assistir o vídeo o texto e o leitor, observei que como futuros profissionais [...]. } \\
\text { Abraços, } \\
\text { Sua aluna, Ana Paula Freitas Soares. }\end{array}$ \\
\hline $3^{\circ} \mathrm{SL}$ & $\begin{array}{l}\text { Muito bom o texto professor. } \\
\text { Mostra-nos como devemos ser curiosos, investigadores, }[\ldots] \\
\text { Um abraço a todos. } \\
\text { Ana Paula. }\end{array}$ \\
\hline & $\begin{array}{l}\text { Olá Joana, Selma, Jandira,Clara e demais colegas. Depois de assistir ao vídeo sobre organizaçáo } \\
\text { do tempo e do espaço na escola relacionei-o com os componentes estudados, principalmente } \\
\text { quando relata sobre [...].Verifiquei também que apesar da escola ser [...]. } \\
\text { Abraços. }\end{array}$ \\
\hline $4^{\circ} \mathrm{SL}$ & $\begin{array}{l}\text { Oi colega. } \\
\text { Concordo plenamente com você. Ao ler o texto de Pedro Demo, percebi que realmente } \\
{[\ldots] \text {. Gostei muito de um parágrafo do texto, que relata [...] }}\end{array}$ \\
\hline & $\begin{array}{l}\text { É isso mesmo Clara. Conforme relata o nosso colega Adilson, essa imagem é mesmo uma } \\
\text { obra de arte }[\ldots]\end{array}$ \\
\hline $5^{\circ} \mathrm{SL}$ & $\begin{array}{l}\text { Cara colega, } \\
\text { Se olharmos apenas o significado dos termos, concluímos que [...] } \\
\text { Espero ter respondido seu questionamento. } \\
\text { Paula }\end{array}$ \\
\hline $6^{\circ} \mathrm{SL}$ & $\begin{array}{l}\text { Oi Mirele, } \\
\text { Concordo com você. É o Estado de Minas Gerais, que diante da grave crise que o regime } \\
\text { republicano [...] } \\
\text { Abraços. } \\
\text { Ana Paula Freitas Soares }\end{array}$ \\
\hline $7^{\circ} \mathrm{SL}$ & $\begin{array}{l}\text { É isso aí Karla, e são nas diferenças, nas particularidades que os seres se completam. Quão } \\
\text { monótono seria, se fôssemos e pensássemos da mesma maneira... }\end{array}$ \\
\hline $8^{\circ} \mathrm{SL}$ & $\begin{array}{l}\text { Oi Clara. } \\
\text { Concordo plenamente com você. A educação [...] } \\
\text { Beijos, } \\
\text { Ana Paula. }\end{array}$ \\
\hline
\end{tabular}

Legenda: $\mathrm{SL}=$ Semestre letivo. Grifos nossos. 
Percebemos que os enunciados são sempre dirigidos a uma ou mais pessoas, o que caracteriza o princípio dialógico presente nas mensagens, já que o sujeito, ao falar, sempre pressupõe um interlocutor (BAKHTIN, 1997). Nas três primeiras mensagens, Ana Paula se dirige claramente ao professor/tutor, ao abrir e ao finalizar a mensagem. A primeira e a segunda mensagens trazem inclusive traços característicos de uma carta pessoal. $\mathrm{Na}$ terceira mensagem ela já insere o grupo ao se despedir (Abraços a todos). A partir da quarta mensagem, postada ainda no $3^{\circ}$ semestre letivo, Ana Paula dirige-se mais aos colegas, individualmente e coletivamente - compartilha, concorda, responde, complementa ideias.

Nascimento (2009) analisa as mudanças na posição enunciativa como uma indicação da construção de um professor autor, a partir do momento em que o aluno, licenciando de Pedagogia, deixa de se colocar no papel de receptor de informaçóes ou executor de tarefas e passa a assumir o controle de significados. Entendemos que essa mesma descentralização da figura do professor acontece quando, nos fóruns, os alunos começam a dialogar entre si e não mais apenas com o tutor, assumindo uma atitude responsiva ativa.

Outro aspecto observado foi como o discurso acadêmico foi se instaurando. Nos primeiros semestres, as reflexões dos alunos se caracterizavam por opiniões, muitas vezes de cunho emocional e, ao longo do tempo, foram se tornando mais formais, sendo racionalizadas. Observando novamente o Quadro 2, podemos perceber esse movimento nas mensagens postadas pela aluna Ana Paula, inclusive na variação presente nos verbos em primeira pessoa - sinto, vejo, observei, relacionei, percebi, verifiquei, concordo - explicitando a forma como a aluna se apropria do discurso acadêmico, passando a considerar o discurso do outro, por meio das relações que estabelece com os objetos de aprendizagem (vídeos, textos, etc.) e das citações.

As práticas discursivas apresentam como elementos constitutivos os enunciados, a forma e o conteúdo (SPINK, 2004). As mensagens apresentadas no Quadro 2 explicitam modificaçóes na forma e no conteúdo, e, como construções enunciativas, são influenciadas pelas condições da produção discursiva. Isso demonstra que a constituição das práticas discursivas vai se dando no contexto da situação.

As trocas discursivas repousam sobre as competências lógicas e os saberes desenvolvidos pelos sujeitos em diferentes contextos sócio-históricos e sobre a interpretação imediata da situação e das tarefas conduzidas durante a interação discursiva (NASCIMENTO, 2007, p.136). 
Assim, vamos compreendendo, por meio das práticas discursivas, os sentidos que vão sendo produzidos, buscando reconhecer nesses espaços de escrita autoral, elementos que indicam as condições de letramento manifestadas pelos sujeitos. Neste ponto, percebemos que nessa escrita encontramos marcas de um letramento acadêmico. Lembramos que já é comum encontrarmos o termo letramento na forma plural, e concordamos com Soares (2002) quando afirma que esses diferentes espaços de escrita, com seus diferentes mecanismos de produção, reprodução e difusão irão resultar em diferentes letramentos. E a autora completa:

A tela, como novo espaço de escrita, traz significativas mudanças nas formas de interação entre escritor e leitor, entre escritor e texto, entre leitor e texto e até mesmo, mais amplamente, entre o ser humano e o conhecimento. [...] a tela como espaço de escrita e de leitura traz não apenas novas formas de acesso à informação, mas também novos processos cognitivos, novas formas de conhecimento, novas maneiras de ler e de escrever, enfim, um novo letramento, isto é, um novo estado ou condição para aqueles que exercem práticas de escrita e de leitura na tela (SOARES, 2002, p.151-2).

Podemos perceber como a escrita nos contextos de autoria aqui examinados significou para os sujeitos uma condição de um letramento realmente plural, conforme explicitam as mensagens a seguir, postadas pelas alunas num momento de autoavaliação e avaliação do curso, no último semestre letivo:

Foi uma fase muito importante para mim, pois tive mais oportunidade de acesso à internet, e com isso aprendi a utilizá-la com mais frequência (Márcia).

As atividades do ambiente virtual além de trazer para o educador uma nova maneira de usar recursos tecnológicos na educação estimulam o aluno a pensar de forma diferente. Neste sentido, percebo mais autonomia ao argumentar fatos e acontecimentos propostos nos fóruns (Eliane).

As escritas nessas atividades contribuiram em meu desenvolvimento intelectual. Fui inserida em um ambiente de discussão, onde me levava a argumentar com bases bibliográficas e que me remetia a expor meu conhecimento adquirido ao longo do curso (Rosane). 
Não podemos, entretanto, deixar-nos seduzir pela tendência a ver o processo como natural para todos os sujeitos. O letramento digital ou acadêmico não é igual para todos os sujeitos, os sujeitos são diferentes, vêm de diferentes realidades. Muitos não se apropriaram desses espaços de escrita e dos gêneros que ali se constituíam. Ao lado de sujeitos que enfatizam seu aprendizado em relação às tecnologias digitais e à escrita acadêmica, temos, embora em número bem menor, outros que, mesmo ao final do curso, ainda se sentem inseguros nesses campos, como podemos ver nas mensagens a seguir:

Ainda tenho muitas dificuldades, algumas coisas ainda preciso de ajuda, mas sei fazer o básico e estou procurando aprimorar a cada dia (Gabriela).

Com muita dificuldade aprendi o suficiente para fazer as atividades. Às vezes erro, mas com ajuda de alguma colega consigo fazer. Mas tenho muita dificuldade ainda (Marina).

Temos nessas mensagens a voz de alunos que, ao concluir o curso ainda demonstram ter dificuldades para usar as tecnologias, além daqueles que por dificuldades de uso e/ou de acesso, não chegaram a postar suas mensagens nos fóruns e questionários onde coletamos esses depoimentos. E, ainda, aqueles que abandonaram o curso ao longo do processo por sentirem-se incapazes diante das demandas de acesso e de uso das tecnologias digitais.

Há todo um universo de motivos que podem levar os sujeitos a abandonarem o curso de graduação a distância ou a concluí-lo mesmo participando pouco do ambiente virtual de aprendizagem ou não terem vivenciado um processo de letramento digital. Dentre esses motivos, podem estar as dificuldades de acesso e a falta de habilidades no uso dos recursos tecnológicos demandados pelo curso, conferindo, assim, um papel limitador e de exclusão das tecnologias. Entretanto, o potencial inclusivo e de mediação da aprendizagem não pode ser ignorado.

Observamos que há, muitas vezes, uma expectativa equivocada em torno das condiçóes de letramento digital e acadêmico com que os alunos chegam à universidade. Bandeira (2009) observou que a própria instituição de ensino superior enxerga o aluno que está ingressando no curso de graduação como usuário pleno das tecnologias, capaz de, logo na entrada, já fazer sua matrícula pela internet e, sem dificuldades, responder às demandas 
de uso das tecnologias ao longo do curso, como se estar preparado para isso fosse algo óbvio. Mas Bandeira observou também que para muitos estudantes, principalmente os das camadas populares, essa preparação não existe, nem antes e nem durante a sua passagem pela universidade. Nesta pesquisa, somos levados a pensar também nas condiçôes de letramento digital de tantos sujeitos moradores em cidades do interior, muitos em zona rural, e em condições, por vezes precárias, de acesso às tecnologias digitais (mais especificamente computador e internet).

Em um estudo acerca das relações de alunos de cursos de graduação em Pedagogia com a escrita nas práticas de letramento acadêmicas, Marinho (2010) encontrou muitas queixas de professores e dos próprios alunos por estes não saberem ler e escrever textos acadêmicos. É como se fosse natural que é na Educação Básica que se aprende a ler e a escrever, não importando o gênero - se passou no vestibular, já sabe. Mas Marinho chama atenção para o fato de que o gênero acadêmico está presente na universidade e não na Educação Básica e que, assim, o sujeito não vivenciou esse gênero antes. A autora cita Bakhtin e acredita que a forma de se pensar o problema

se apoia em uma concepção enunciativa da linguagem, especialmente na teoria dos gêneros de Bakhtin, para a qual o domínio de um gênero depende da experiência, da inscrição dos indivíduos nas esferas que os produzem e deles necessitam (MARINHO, 2010, p.383).

Neste estudo, fomos levados a compreender que a apropriação do gênero caracteriza, assim, o processo de letramento vivenciado pelo sujeito e favorece a sua inserção em determinado campo discursivo ou esfera social. Conforme nos lembra Bakhtin (1997, p.304), "é de acordo com nosso domínio dos gêneros que usamos com desembaraço” e esse domínio se adquire por meio da experiência, da vivência dentro daquele contexto em que o gênero se produz.

Compreendendo que o fenômeno do letramento está intimamente relacionado aos diferentes gêneros discursivos e que estes, por sua vez, são constituídos por "um repertório aberto e heterogêneo de formas de enunciados que vão se organizando, ao longo do tempo histórico, relacionados a determinados conteúdos e situações sociais" (GOULART, 2007, p.47), veremos que a condição letrada inclui diferentes estratégias de uso da língua, nos diferentes contextos e experiências vividas pelo sujeito, inclusive na sua atuação em um ambiente virtual de aprendizagem, no contexto acadêmico. 


\section{CONSIDERAÇÕES FINAIS}

Durante este trabalho, analisamos, em um ambiente virtual de aprendizagem, processos de letramento a partir da apropriação de novos gêneros, bem como a multimodalidade, que pode estar presente e exercer um papel determinante. Nesse ambiente, temos o leiaute da tela, blocos de texto, elementos gráficos e muitos links, sendo que diferentes escolhas podem ser feitas por meio deles.

Nos exemplos apresentados, percebemos que a multimodalidade não existe apenas a partir do uso de imagens gráficas ou de recursos de sons ou animações. A escrita pode ser vista como blocos de texto na tela e isso é uma gramática visual, onde a multimodalidade está presente, em relação estreita com o exercício da autoria, influenciando diretamente as escolhas, a navegação e a escrita online. Assim, é possível reconhecer a multimodalidade do texto a partir, por exemplo, de sua estruturação e apresentação na tela. A estrutura não sequencial e não linear de um fórum é um aspecto multimodal, assim como as diferentes formas de apresentar um texto (cores, espaçamentos, recuos, densidade, caixa alta, destaques etc.). Quando percebemos a escrita sendo tratada como blocos de texto, seja nas mensagens dos fóruns ou nas contribuições individuais nos wikis, confirmamos, como Kress (2003), que o leiaute também influencia a estrutura textual. Segundo o autor, consequentemente, recebem influência os significados do texto, a organização das ideias e as estruturas do conhecimento.

A multimodalidade se faz presente pela lógica sob a qual a tela e o que nela aparece estão. Reconhecer a multimodalidade no ambiente virtual de aprendizagem nos tem feito refletir sobre a sua composição, sobre os diferentes elementos disponíveis na tela e como eles concorrem na construção de significados. Os aspectos multimodais podem favorecer a navegação e a escrita mais ricas e criativas e, consequentemente, que estimulem a iniciativa e a tomada de decisóes, justamente por seu aspecto primeiro de possibilitar escolhas nas formas de representação e comunicação, a partir dos diferentes meios e modos (KRESS, 1997). Esses espaços de escrita são multimodais também porque neles o texto se constrói sob a influência da fala e da escrita - linguagem do dia a dia e linguagem acadêmica. São espaços que podem favorecer a expressão e a socialização de ideias e vivências, a comunicação, enfim. Num curso semipresencial ou totalmente a distância, tais espaços são essenciais para viabilizar o processo de letramento digital e acadêmico. 
Analisando a escrita online, reconhecemos ali a constituição e a apropriação de gêneros discursivos característicos daquela esfera de comunicação verbal - o gênero digital e o gênero acadêmico. A filosofia da linguagem permitiu-nos perceber essa dimensão da interação verbal que ali se constituía, fortemente marcada pela realidade imediata e pelo meio social mais amplo. Os espaços de autoria (fóruns, blogs e wikis) com os quais trabalhamos nesta pesquisa representam espaços sociais de manifestação de novos gêneros discursivos e de convivência com os gêneros já utilizados pelos sujeitos, numa perspectiva híbrida entre o oral e o escrito e entre o novo e o já conhecido.

Esse olhar nos possibilita ainda perceber a escrita dos alunos no ambiente virtual não apenas sob os aspectos linguísticos, mas principalmente sob os aspectos socioculturais. Quando buscamos compreender por que o texto é escrito, para quem é escrito, como é escrito e o que mais podemos perceber a partir daquela escrita, estamos reconhecendo o processo educativo nesse ambiente como linguisticamente e socialmente constituído. E toda essa construção se dá a partir de uma ocasião social (KRESS, 1989), das condiçōes de produção, da esfera de comunicação verbal.

$\mathrm{Na}$ educação a distância, em que o leitor (aluno ou tutor) encontra-se distante temporalmente e geograficamente de quem produziu ou escreveu cada tela, compreender essa construção de significados pelo sujeito muito pode contribuir no planejamento e na organização dos ambientes virtuais de aprendizagem. E, principalmente, a análise da escrita dos alunos sob tais perspectivas muito dão a conhecer sobre esses sujeitos e o seu processo de aprendizagem.

A proposição que norteou este trabalho foi a de que possibilitar aos sujeitos oportunidades de expressão e de escrita, individual e coletiva, num ambiente virtual de aprendizagem favorece o processo de letramento digital e acadêmico. $\mathrm{O}$ meio pelo qual nos colocamos a buscar por essas respostas foram as práticas discursivas expressas na escrita online, considerando que estas poderiam, ao mesmo tempo, ter sua produção favorecida pelos contextos de autoria e, ainda, indicar o processo de letramento digital vivenciado pelos sujeitos. Mais do que isso, as práticas discursivas revelaram a apropriação de novos gêneros discursivos - o digital e o acadêmico. Analisando as condições de letramento manifestadas, pudemos concluir que tais condiçóes se deram por meio da apropriação de novos gêneros discursivos, possibilitada pela experiência vivenciada nos contextos de autoria online. 
Esta investigação, dentro de suas limitações, procurou destacar o papel determinante da autoria em ambientes virtuais de aprendizagem, reconhecendo a constituição e consolidação de novos gêneros - digital e acadêmico - explicitados nas interações entre os sujeitos e destes com o ambiente virtual, por meio da escrita online. A apropriação do gênero caracteriza, assim, o processo de letramento vivenciado pelo sujeito e favorece a sua inserção em determinado campo discursivo ou esfera social.

\section{REFERÊNCIAS}

BAKHTIN, Mikhail. Os gêneros do discurso. In: BAKHTIN, Mikhail. Estética da criação verbal. $2^{a}$ ed. São Paulo: Martins Fontes, 1997, p.277-326. (1ª edição, 1992; edição original em russo, 1979).

BAKHTIN, Mikhail. Marxismo e filosofia da linguagem. 12a ed. São Paulo: Hucitec, 2006. (1 a edição: 1929).

BANDEIRA, Daniela Perri. Trajetórias de estudantes universitários de meios populares em busca de letramento digital. 2009. Tese (Doutorado em Educação). Universidade Federal de Minas Gerais, Belo Horizonte, 2009.

CHARAUDEAU, Patrick; MAINGUENEAU, Dominique. Dicionário de análise do discurso. Coordenação da tradução Fabiana Komesu. São Paulo: Contexto, 2004. COSCARELLI, Carla Viana. Entre textos e hipertextos. In: COSCARELLI, Carla Viana (Org.). Novas tecnologias, novos textos, novas formas de pensar. $3^{\text {a }}$ ed. Belo Horizonte: Autêntica, 2006, p.65-84. (1'a edição: 2002).

GOULART, Cecília. Letramento e novas tecnologias: questôes para a prática pedagógica. In: COSCARELLI, Carla Viana; RIBEIRO, Ana Elisa (Org.). Letramento digital: aspectos sociais e possibilidades pedagógicas. $2^{\mathrm{a}}$ ed. Belo Horizonte: Ceale; Autêntica, 2007. (1ª edição: 2005).

KRESS, Gunther; VAN LEEUWEN, Theo. Reading images: the grammar of visual design. London: Routledge, 1996.

KRESS, Gunther. Linguistic processes in sociocultural practice. Oxford University Press, 1989.

KRESS, Gunther. Before writing: rethinking the paths to literacy. London: Routledge, 1997.

KRESS, Gunther. Literacy in the New Media Age. London: Routledge, 2003.

KRESS, Gunther. Multimodality: a social semiotic approach to contemporary communication. London: Routledge, 2010. 
MACHADO, Irene. Gêneros Discursivos. In: BRAIT, Beth (Org.). Bakhtin: conceitos-chave. $4^{\mathrm{a}}$ ed. São Paulo: Contexto, 2007, p. 151-166. (1 a edição: 2005).

MARCUSCHI, Luiz Antônio. Gêneros Textuais: definição e funcionalidade. In: DIONISIO, A.; MACHADO, A. R.; BEZERRA, M. A. (Org.). Gêneros Textuais \& Ensino. $5^{\mathrm{a}}$ ed. Rio de Janeiro: Lucerna, 2007, p.19-36. (1'a edição: 2002).-

MARINHO, Marildes. A escrita nas práticas de letramento acadêmico. Revista Brasileira de Linguística Aplicada. Belo Horizonte, v.10, n.2, p.363-386, 2010.

MEDEIROS, Zulmira. Letramento digital em contextos de autoria na internet. 2011. Tese (Doutorado em Educação). Universidade Federal de Minas Gerais, Belo Horizonte, 2011.

NASCIMENTO, Silvania Sousa do. A linguagem e a investigação em Educação Científica: uma breve apresentação. In: NARDI, Roberto (Org.). A pesquisa em Ensino de Ciências no Brasil: alguns recortes. Bauru: ABRAPEC, 2007, p.131-142. NASCIMENTO, Silvania Sousa do. Memórias e posições enunciativas na formação de professores para as séries iniciais do ensino fundamental. Educar em Revista, Curitiba, n.34, p.149-166, 2009.

SOARES, Magda. Novas práticas de leitura e escrita: letramento na cibercultura. Educação e Sociedade: Revista de Ciência e Educação, Campinas, v.23, p.143-160, dez./2002.

SPINK, Mary Jane (Org.). Práticas discursivas e produção de sentidos no cotidiano: aproximações teóricas e metodológicas. $3^{\mathrm{a}}$ ed. São Paulo: Cortez, 2004. (1 $1^{\mathrm{a}}$ edição: 1998).

Recebido em: 14/11/2013. Aprovado em: 30/05/2014. 